\title{
The Sisyphean Discipline: A Précis of "An Unnatural History of Religions"
}

\author{
LEONARDO AMBASCIANO*
}

"I'm a pessimist because of intelligence, but an optimist because of will. In all circumstances I think first of the worst possibility in order to set in motion all the reserves of my will and be in

a position to knock down the obstacle."

Antonio Gramsci ${ }^{1}$

History of Religions is a very strange discipline.

Despite its highly problematic epistemic status, a questionable methodological toolbox, and a troubling past, this discipline has managed to carve a uniquely successful niche in modern academia, ultimately becoming a safe haven for apologetic scholars willing to bend or break the rules of scientific research to justify religious or spiritual beliefs. This is the contradiction that I explore in my recent book entitled An Unnatural History of Religions: Academia, Post-truth and the Quest for Scientific Knowledge (henceforth, AUHR). ${ }^{2}$ AUHR looks back at the whole history of the History of Religions (HoR) in a scientifically informed and updated way, from Darwin to neuroscience, with a special focus on its method(s)

* I would like to thank the editors of Religio and my former colleagues at the Department for the Study of Religions, Masaryk University, Brno (CZ) - in particular Michaela Ondrašinová and Aleš Chalupa - for giving me the opportunity to recap the main arguments of my book in this contribution. As the book develops themes and topics introduced during my 2016 visiting lectureship at Masaryk University, it seems only fitting to dedicate this contribution to all my former students.

1 Antonio Gramsci, Letters from Prison I, ed. Frank Rosengarten, trans. Raymond Rosenthal, New York: Columbia University Press 2011 ( $1^{\text {st }}$ ed. 1994), 299 (19 December 1929).

2 Leonardo Ambasciano, An Unnatural History of Religions: Academia, Post-truth and the Quest for Scientific Knowledge, London - New York: Bloomsbury 2019. 
and theory (or lack thereof). Despite the stable scientific scaffolding conceived by brilliant precursors such as David Hume and Charles R. Darwin, and a scientific framework further improved by scholars such as Edward B. Tylor and James G. Frazer, fideistic and crypto-theological issues came to dominate the field and eventually led to an academic U-turn towards anti-scientific approaches. The field has thus lent its academic credibility to a wide array of anti-scientific endeavours covering the whole gamut of the socio-political spectrum, from antidemocratic, racist, reactionary Interwar politics, to the spiritual reawakening of the New Age and, finally, postmodernism.

As a successful belief system proven to survive any disconfirmation, the HoR epitomizes the everlasting anti-scientific temptation within both the Humanities and the Social Sciences. Notwithstanding a quite remarkable number of scholars who have tried to advance and recommend a scientific approach, the field has been constantly held back by its intuitive cognitive appeal: folk religious ideas loom over the field, and with each generation their resurgence threatens to undo most of the previous scientific achievements. What follows is a brief and merely illustrative recap of the main arguments of the book.

\section{"Natural" does not mean "good"}

As I wrote in the "Preface: Ghosts, Post-truth Despair, and Brandolini's Law", the reason for, and the ultimate cause of, the continuous presence of anti-scientific inclinations in the HoR is that

nature, in the guise of deep-historical, impersonal, aimless and meaningless evolutionary dynamics, has provided us, Homo sapiens, with a software that, for the mere purpose of its hardware self-maintenance, survival and replication, is inclined to produce immediate, personal, intentional and purposeful answers. ${ }^{3}$

In other words, our computational machinery is the product of evolution, a system of neurophysiological networks cobbled together as the result of constant, purposeless bricolage or tinkering, eventually accumulating and recycling different parts for different uses with different adaptive values. We are cognitively limited, and our cognition is constrained by its primate origin: social cognition has left its mark on many processes, resulting in an unintelligent design inherently flawed and marred by biases and fallacies. Evolutionary pressures sieved heuristics and logical shortcuts that were sufficiently useful for immediate survival in specific socio-eco-

3 L. Ambasciano, An Unnatural History..., xi. On the hardware-software analogy cf. ibid., 179 , note 1 . 
logical environments. ${ }^{4}$ To cut a long story short, those biases suggested effortless ways to develop an all-encompassing and satisfying explanation for the whole cosmos, humankind, and all things in between. ${ }^{5}$ Theologies flourished. However, even though epistemic satisfaction offers no guarantee of a reliable description of reality, it can be of help in accepting justifications for the status quo. Once those explanations were implemented within a new and radically different ultrasocial environment made up by thousands, if not millions, of unrelated strangers, mythological machines were born, that is, "the dynamic use of mythographical discourses to reproduce power structures and engender an institutional system of authority within an "imagined community"" 6 Under these societal circumstances, both intra-group, intra-cultural variation and neurodiversity accounting for non-theistic worldviews and rational, non-intuitive explanations were neglected, forcibly rejected, or violently silenced. ${ }^{7}$

And yet, despite the "occasional outburst of religious intolerance", the conflict between science and religion remained almost confined to a "zerosum guerrilla war" ${ }^{\prime}$ - until the Scientific Revolution. Slowly but steadily, science - intended as a set of tools and practices to bypass such intuitive biases and fallacious elaborations thanks to a collective, cumulative, peerreviewed process of data gathering, interpretation, evaluation, qualitative assessment, and quantitative analysis based on critical thinking, intellectual freedom, and rigorous $\operatorname{logic}^{9}-$ began to gain the upper hand. On the shoulders of the unorthodox giants of the intellectual past, some scholars began to think out of the theological box. ${ }^{10}$ First came David Hume's ingenious, demystifying psychological and ethnographic deconstruction of religion as a natural outcome of cognitive biases and human fears. Then, Darwin's ground-breaking evolutionary theory broke in. With Darwin's calm prose and painstakingly documented research, theodicy lost cogency, and any Abrahamic, Western, modern theological justification for a warranted religious ontology was irreparably debunked. Nay, all worldwide

4 See for instance Christopher Boehm, Hierarchy in the Forest: The Evolution of Egalitarian Behavior, Cambridge, MA: Harvard University Press 1999; Robin Dunbar, Human Evolution, London: Penguin 2014.

5 As I have noted in AUHR, "although still used indiscriminately, 'myth' is an all-encompassing label, or a wastebasket taxon, which includes cultural representations whose origins, functions, aims and morphology can differ dramatically"; L. Ambasciano, An Unnatural History..., 180, note 3.

6 Ibid., 8. On Furio Jesi's (1941-1980) conceptualization of "the mythological machine" see Enrico Manera, Furio Jesi: Mito, violenza, memoria, Rome: Carocci 2012.

7 L. Ambasciano, An Unnatural History..., 142.

8 Ibid., xiv.

9 Ibid., 148-151.

10 Ibid., xiv. 
mythological machines, past and present, were deconstructed, and proved lacking and faulty. ${ }^{11}$ The takeaway was clear: intuitions can be deceitful and harmful. Reality can be far stranger than fiction. ${ }^{12}$

Religion was finally and scientifically resolved as something "natural" - but there was a catch. Even though religion is the natural outcome of specific evolutionary causes, that does not mean that religion is "naturally good". On the contrary, religion may be as natural as heart attacks and strokes are natural. The paradox is that the HoR has confused Hume's is-ought problem, to the point that the discipline has promoted an unnatural understanding of religion, as if there were cardiac surgeons "actively downplaying, minimizing or misinterpreting the impact of the ultimate and proximate causes behind cardiovascular issues, encouraging the usual bad habits which lead to such health problems ..., and judging the very causes of such tragic outcomes as naturally non-problematic or unavoidable". ${ }^{13}$ This may come across as rather perplexing. Shouldn't science be triumphant at last? Not at all, because, as hinted above, "ordinary human cognitive construals that provide the scaffolding for intuitive explanations find the very logic of evolution counterintuitively baffling". ${ }^{14}$ Coming full circle, when it comes to the study of religions,

the most appealing and successful study of religion(s) is that which has answered positively to, and piggybacked on, these immediate, agentive, essential and teleological non-evolutionary and virtually anti-scientific tenets. Institutions have exploited this penchant, and most scholars in the field, eager to manipulate socio-cultural evolutionism, have provided supportive ethnocentric, theological and/or racial interpretations to the HoR as a whole. ${ }^{15}$

\section{(Post-)Truth to power}

Science and critical thinking require inter-generational, ongoing, institutional support to suppress intuitive biases such as confirmation bias, teleological promiscuity, essentialism, etc. If left unchecked, even critical thinking can be hijacked by intuitive biases and used to elaborate on false premises - as is the case for highly counterintuitive religious dogmas. No institutionally sanctioned or socially accepted scientific advance can be considered written in stone. It takes just one small tweak and the whole edifice crumbles down: if a hierarchical, ultrasocial institution happens to be contaminated by anti-scientific ideologies, the domino effect reverber-

\footnotetext{
11 Ibid.

12 Ibid., 148-151, 171.

13 Ibid., xiv.

14 Ibid.

15 Ibid.
} 
ates through the whole system. Whenever reality is refused to be acknowledged and expertise delegitimized, post-truth kicks in: something is believed to be true because it is emotionally appealing and socially rewarding to believe so. Mythological machines can be rebuilt anew. ${ }^{16}$

Religion was literally built on post-truth. Indeed, the HoR stands out as a noteworthy case study for the prehistory of post-truth: historians of religions mastered post-truth approaches in which pseudoscientific immunizing strategies have successfully shielded the field from external criticism. Despite the field's relatively recent establishment, a historiographical account of the study of religion reveals that institutionalised religious posttruth is as ancient as human ultrasociality itself - and warnings against it are just as old. ${ }^{17}$ What's new today is the global, real-time, online socialmedia dimension and immediate political weaponization of post-truth. The past and present development of the HoR reflects the constant reversion to the anti-scientific mean and to intuitive biases. All the more, I contend in AUHR that the HoR has been a crucial historical nexus and a hotspot for institutional post-truth. Unfortunately, this also means that the amount of work needed to correct the course of the discipline is quite frankly beyond imagination:

Brandolini's Law states that "the amount of energy needed to refute bullshit is an order of magnitude bigger than to produce it" ..., and the current HoR is replete with bullshit, i.e. the disregard for truth and the willingness to engage in fakery and postmodern "instant revisionism" for the sake of it - and for prestige and fame as well. ${ }^{18}$

What I hope to achieve with $A U H R$ is to stimulate a serious inter-disciplinary discussion about the widespread presence of fideism in the historical study of religion(s), not to do away with this topic, but to put an end once and for all to the pseudoscientific and degenerating research programmes in the field. As I note at the end of the introductory chapter, "for the sake of the survival of the social-scientific study of the history of religions, the discipline called HoR must go". ${ }^{19}$ But is speaking truth to power a good strategy when the watchmen who should preside over the discipline have been themselves knee-deep in post-truth biases and prone - as we will discover later on - to spiritual quackery and postmodern gobbledygook as well?

16 Ibid., 153.

17 Ibid., xii-xiii.

18 Ibid., xvii. Cit. from Phil Williamson, "Take Time and Effort to Correct Misinformation", Nature 540/7632, 2016, 171; on "bullshit" as a philosophical concept see Harry G. Frankfurt, On Bullshit, Princeton - Oxford: Princeton University Press 2005.

19 L. Ambasciano, An Unnatural History..., xvii. 


\section{State of the union}

The first chapter, entitled "An Incoherent Contradiction", tackles the problematic status of the subject matter, which I have defined as follows:

[The HoR] has been and still is usually conceived of as the study of religion (singular) and/or religions (plural) via comparative methods aimed at recovering and enhancing similarities (and, more rarely, differences) among religious beliefs and practices from the ancient past to the present day. The discipline aims at gaining an insightful and precise classification of religious phenomena which, in turn, is supposed to enlighten the religious contents of human cultures from the first written documents to the newest religious movements, from the ethnographic accounts of bold nineteenth-century explorers to the religious vagaries of the Internet and the spiritual, digital-age miscellanea available online. ${ }^{20}$

Despite my attempt at advancing some sort of general definition, the modern discipline of the HoR is characterized by a frustrating lack of consensus about methods, theory, aims, and objects of inquiry, so much so that the HoR can be considered a patchwork discipline that lacks any sufficient common ground, split along the fault line of fideism and cryptotheology, on one side, and historiographical approaches, on the other. The lack of a shared definition of what "history" and "religion" should represent is revealed as the source of constant tension in the field, where historiographical and materialistic approaches struggle to coexist with faithful, theological, or spiritual(istic) accounts. Historically speaking, this demarcation has differentiated the main trends of, respectively, Historicism and Phenomenology, two fundamentally irreconcilable ways to approach method and theory. The very existence of the discipline itself is a puzzle: as recognized by many a researcher in the field, HoR has always been in a perpetual state of unsolvable crisis. ${ }^{21}$

The cognitive grip of intuitive biases supplies the solution to this contradiction, and it is reflected in the fact that the most successful analytical tools ever devised by the HoR can be identified in the concepts of sui generis and homo religiosus, both used to advance a new natural theology in which religious explanations are tautologically adopted as the academic key to making sense of religion itself. While homo religiosus is a (pseudo-) heuristic tool used to show and convince others that religion is a universal given (which relates to the alleged existence of a transcendental reality), sui generis means "unique, uncaused by something else, irreducible, one

20 Ibid., 1-2.

21 Ibid., 9. 
of a kind, pre-political, pre-social, the presumption that our object of study is a pristine experience that cannot quite be put into words". 22

Basically, HoR has built a whole system of understanding while piggybacking the intuitive cognitive biases of human cognition and elaborating on the assumptions of folk religion. As I will briefly explain shortly, it is not by chance that the HoR has provided interested scholars a way to shield their biases and support a renovated meta-theological apologetics. In this new environment, religion, various traditions, and folk tales are assumed as trustworthy because everyone (reportedly) believes in some sort of religion, a logical argument marred by such fallacies as the appeal to mass opinion and truth by authority. ${ }^{23}$ Quite ironically, the processes that between the $18^{\text {th }}$ and $19^{\text {th }}$ centuries underlay both the birth of natural theology and the historical study of religion(s) - that is, the accumulation of proofs concerning the (alleged) divine organization of the cosmos and the theological efforts to make sense of the disconfirming evidence - brought about the same unsatisfactory result, leading in both cases to non-theological scientific explanations. ${ }^{24}$

\section{To darwinize or not to darwinize?}

In order to disentangle the ultimate and proximate roots of the HoR, the second chapter ("The Deep History of Comparison") isolates and identifies a set of basic instruments and basic features traditionally used to make sense of similarities and dissimilarities among cultures and religions and employed to classify religions:

- essentialism, a cognitive set of biases assuming a fixed, immutable nature in the things studied;

- emicletic methodologies - that is, the different approaches towards religious materials either entailing, respectively, an inside-out, belief-sharing and participatory approach or a focus on a more critical outside-in inquiry;

- inter-religious conjectural assimilation between different deities and different pantheons (with the specific case study of Graeco-Roman religions vs. ancient Christianity). ${ }^{25}$

22 Ibid. Cit. from Russell T. McCutcheon - Thomas J. Coleman III, “'Religion' as 'sui generis"' [online], The Religious Studies Project, <https://www.religiousstudiesproject.com/podcast/russell-mccutcheon-on-religion-as-sui-generis/>, 13 January 2014 [15 May 2017].

23 L. Ambasciano, An Unnatural History..., 6.

24 Ibid., 9-11.

25 Ibid., 13-17. 
In this sense, as noted by Jonathan Z. Smith, religions are not just the passive subjects of comparison and classification; they become the engine of comparison by suggesting or imposing the very criteria according to which out-groups should be classified. ${ }^{26}$ However, this is just half of the story. What I have tried to do in this chapter is to highlight that such biases and procedures have a deep evolutionary history, strictly tied to our mammalian ancestry and to our panhuman primate heritage. To cut another long story short, socioecological items are intuitively classified in order to discern between useful and futile objects, between friends and enemies, etc. As a result, the cognitive toolbox behind this "Us vs. Them" psychosocial demarcation has been intuitively exploited in every human society past and present - and elevated to the status of paradigmatic tool during the conceptual prehistory of the HoR. ${ }^{27}$

After the Age of Discovery, with the increased knowledge and contact between Western and non-Western peoples around the globe, we witness the development of fallacious inductive reasoning based on premises whose degree of truth was assumed as an a priori criterion: if religious dogmas are true, then natural religion, the idea that the quintessential trait of humankind is religion, and sacred history, that is, the Judeo-Christian idea of a precise spatio-temporal origin of humankind tied to a divine creation, can constitute the basis for a rational cross-cultural comparison. ${ }^{28}$ However, the threefold interaction of the Scientific Revolution, the Age of Discovery, and the creation of international academic networks was about to shake the foundation of such an idea. Theology-free inquiry in the field was the progressive result of the very accumulation of theological comparative enterprises increasingly at odds with their unsettling and unexpected results, here exemplified by the works of Jean Bodin, Herbert of Cherbury, Bernard Fontanelle, Giambattista Vico, and David Hume.

Eventually, this exercise in empirical observation coalesced in postDarwinian Victorian times to form the first comparative science of religion (or comparative religion). However, despite the ground-breaking scientific works of Edward B. Tylor, Friedrich Max Müller, and James G. Frazer, whose research and legacy are also examined in this chapter, the field has never reached a unanimous agreement on its founding figures. Engels, Marx, Weber, Malinowski, Durkheim, Freud, des Brosses, McLennan, Lafitau, Feuerbach, Comte, Hubert, Mauss, Lévy-Bruhl, James, and Nietzsche are just a few of the names usually acknowledged as co-creators,

26 Ibid., 13. Cf. Jonathan Z. Smith, "Classification", in: Willi Braun - Russell T. McCutcheon (eds.), Guide to the Study of Religion, London: Cassell 2000, 35-44: 38.

27 L. Ambasciano, An Unnatural History..., 16.

28 Ibid., 20. 
designers, or innovators of the HoR (and recalled in the chapter). ${ }^{29}$ Reflecting the appeal to purity typical of the no true Scotsman fallacy, almost each and every historian of religions has resorted to an idiosyncratic list of personal preferences, sometimes even rejecting those scholars most interested in a scientific approach and preferring instead controversial and anti-modernist figures like Johann J. Bachofen, Georg F. Creuzer, or Andrew Lang. ${ }^{30}$ To recap, "each one of these figures stands as something of a maverick, an intellectual nomad at once inspiring and irritating but never truly constitutive of the discipline". ${ }^{31}$

Two among those earliest scholars were particularly vocal about the role of evolution. In 1909, Jane Ellen Harrison “attributed the 'creation' of the modern 'scientific study of Religions' to 'Darwinism' itself'. ${ }^{32}$ A few years later, Robert R. Marett highlighted that the anthropological study of religion could not be envisaged without referring to evolution, adding that scholars "need to darwinize actively" in order to connect the deep history of life with the whole span of human history and anthropology. ${ }^{33}$ This evolutionary turn in the field is tackled in the following chapter entitled "The Darwinian Road Not Taken", entirely dedicated to the impact of Darwinian evolution on the historical study of religion(s). The works of Charles R. Darwin, in particular The Origin of Species (1859) and The Descent of Man (1871), are closely scrutinized as examples of both a sound historiographical methodology and an epistemically warranted theory. Not only did they both give momentum to the scientific study of religion but they also tackled religion with an unprecedented clarity. Moreover, they still represent a masterpiece of historical inquiry to the point that, as historian of science Frank J. Sulloway maintains, "a good case can be made for considering Charles Darwin the greatest historian of all time". 34

29 Ibid., 33.

30 Ibid., 32.

31 Ibid., 33. Cit. from Tomoko Masuzawa, "Origin", in: Willi Braun - Russell T. McCutcheon (eds.), Guide to the Study of Religion, London: Cassell 2000, 209-224: 217.

32 L. Ambasciano, An Unnatural History..., 45. Cit. from Jane E. Harrison, "The Influence of Darwinism on the Study of Religions", in: Albert C. Seward (ed.), Darwin and Modern Science: Essays in Commemoration of the Centenary of the Birth of Charles Darwin and the Fiftieth Anniversary of the Publication of the Origin of Species, Cambridge: Cambridge University Press 1909, 494-511: 494.

33 L. Ambasciano, An Unnatural History..., 35. Cit. from Robert R. Marett, Anthropology: Revised Edition, London - New York: Williams and Norgate Ltd. - Henry Holt and Co. 1914 ( $1^{\text {st }}$ ed. 1912), 9.

34 L. Ambasciano, An Unnatural History..., 37. Cit. from Frank J. Sulloway, Born to Rebel: Birth Order, Family Dynamics, and Creative Lives, London: Abacus 1998 (1 ${ }^{\text {st }}$ ed. 1996), 366. 
However, Darwin's proposal could not be easily accepted for it inevitably entailed a materialistic account of human behaviours while shaking the foundational dogmas of institutional religions. Accommodationist responses to assuage this tension resulted in convenient manipulation of scientific topics while outright rejection led to the reaffirmation of the traditional status quo. In the field, these possibilities modulated in different ways the idea of human exceptionalism - that is, an unbridgeable gap between human and nonhuman animals, which I have further deconstructed into four main historical and cultural components (i.e., pithecophobia; evolutionary teleology; orthogenesis; anthropodenial). ${ }^{35}$

Religion was reputed one of the most defining characters of humankind - if not its quintessential feature - but the first topic to be debated between scholars of religion and evolutionists was language. This was not something completely unexpected. Max Müller's rejection of a gradual evolution of human language from animal communication in favour of a (divine) linguistic Rubicon, and his diatribe with Darwin himself, are presented as the very first instances of the problematic relationship between modern natural science and the historical study of religion(s). ${ }^{36}$

\section{All around the world}

With the comparative science of religion set to become the Victorian "theory of everything", that is, the subject able to resolve any important question about the development of humankind, the field began to become swamped by inadequate peer review and insufficient epistemological assessment. Eventually, the state-of-the-art consensus focused on mythology and agnostic or atheistic approaches heralded by Tylor, Frazer and (with some caveats) Max Müller - approaches that had been the subject of consistent and continuous attacks - was at last subverted from the inside by William Robertson Smith's sociological "scientific theology". 37 Other Victorian scholars, most notably Harrison and Lang, also contributed to question the discipline from within, letting in biases, fallacies, spiritualism, the paranormal, and the supernatural. ${ }^{38}$ The infiltration of accommodationist or frankly theological perspectives brought about the end of the Victorian science of religion. The discipline, thus, moved to Continental Europe first, and the United States later. The historical study of religions morphed into distinctive national trends, each one chronologically built on

35 L. Ambasciano, An Unnatural History..., 41.

36 Ibid., 46-48.

37 Ibid., 57-62.

38 Ibid., 79-82, 153-155. 
the previous ones, and each one increasingly dedicated to non-scientific ways to approach religion(s):

- the Netherlands' morphology and phenomenology, which struggled to re-confessionalize the discipline after its initial foray into the scientific comparativism inherited from the Victorian school. This process culminated in the institutional and disciplinary role played by the theologian Gerardus van der Leeuw;

- the Germanophone Kulturkreislehre and Urmonotheismus, dominated by Catholic priest Pater Wilhelm Schmidt and his Anthropos school of apologetic "ethnotheology";

- Italian Historicism, with Raffaele Pettazzoni as its most prominent scholar. All along its academic career, Pettazzoni strived to combine a historiographical approach with phenomenological understanding, only with ambiguous and epistemologically inconsistent results;

- Romanian hermeneutics and metapsychoanalysis of folklore, heralded first and foremost by Mircea Eliade, who, during the Interwar period, advocated an ultranational approach ${ }^{39}$ heavily dependent on a priori supernatural and paranormal beliefs;

- finally, contemporary HoR, which rose to worldwide recognition mostly thanks to European scholars who emigrated to the United States during the second half of the $20^{\text {th }}$ century (e.g., Joachim Wach and Eliade himself). ${ }^{40}$

The foundation and interweaving of a network of international scholarly associations sanctioned the academic respectability of the whole endeavour. This process resulted in the foundation of the International Association for the History of Religions (IAHR) in 1950, thanks to the organizational efforts of van der Leeuw and Pettazzoni. However, given the unstable amalgam between emic phenomenology and etic historicism, science itself became the designated victim of this institutionalization, for the new HoR, while officially donning a scientific entitlement and a place at the High Table of academia, tolerated or endorsed a fideistic approach as well as a (meta-)theological and spiritual advocacy. ${ }^{41}$

Despite the occasional mutiny against the dominance of non-scientific methods and theories, the discipline was bound to proceed along a phenomenological and hermeneutic path. The fifth chapter ("Eliadology") reviews in depth the works of Mircea Eliade, probably the most important, renowned, and successful historian of religions and phenomenologist of

39 On ultranationalism see Roger Griffin, Fascism: An Introduction to Comparative Fascist Studies, Cambridge, UK: Polity Press 2018.

40 L. Ambasciano, An Unnatural History..., 66-91.

41 Ibid., 88-90. 
the past century - if not ever. Originally from Romania, Eliade rose to disciplinary stardom after his appointment at the University of Chicago Divinity School in the mid-1950s. As Eliade's works exemplify the major problems of the coeval HoR, I have mainly focused on the foundations of Eliade's disciplinary proposal, highlighting his methodological shortcomings and his epistemological blunders. In particular, the chapter emphasizes Eliade's understanding of prehistory, human evolution, shamanism, and folk-psychoanalytical assumptions. The intellectual roots of Eliade's concepts are identified in their formation in Interwar Romania, in a cultural environment largely dominated by a post-truth, ultranational, and reactionary re-invention of tradition. This explains Eliade's penchant for esotericism and spiritual and anti-Darwinian evolutionism, all elements that he brought to the United States and that, in turn, influenced, converged with, and merged into the New Age movement. The success of Eliade's disciplinary proposal constrained any further development in the field while strengthening its anti-scientific anti-reductionism to safeguard the field from criticism, and transformed the HoR into a Lakatosian degenerating research programme, i.e., full-fledged pseudoscience.

\section{Be careful what you wish for}

Eliade's legacy in the field is assessed in the first part of the sixth chapter ("The Demolition of the Status Quo"). The controversial aspects of Eliade's biography, i.e., his political involvement in right-wing extremist Interwar Romanian movements, are appraised as part and parcel of the political undertones of his HoR. The troublesome assumptions flowing from the Eliadean conservative agenda are identifiable in his disciplinary sexism, the prehistoric religiosity, the primacy of shamanism, the morphological phenomenology, and the classificatory system he supported. Poignant criticism stemming from his Chicago colleagues and students began to gain momentum from the late 1970s onwards, and the pivotal works of the following scholars are recalled and included for the first time in a comprehensive history of the field along with their major works and contributions: Rita M. Gross, Henry Pernet, Mac Linscott Ricketts, Ioan P. Culianu, Jonathan Z. Smith, and Bruce Lincoln. ${ }^{42}$

Meanwhile, a younger generation of scholars, profoundly affected by the discovery of the discipline's political and ideological implications and mainly building on Smith's and Lincoln's poststructural criticism, began to reverse-engineer the HoR. This process resulted in the creation of the new field of Religious Studies and the sub-field of Method and Theory to

42 Ibid., 117-135. 
dismantle the social construction of power discourses, conservative agendas, and coercive top-down control both in the first-order and second-order documentary record (respectively, ancient documents and modern interpretations). While the advent of such poststructuralist approaches represented a much-needed corrective to deconstruct the antidemocratic and anti-scientific nature of past research in the field, the spread of postmodernism resulted, once again, in the rejection of scientific research. While this is a still much debated and quite complex topic, I have tried to differentiate poststructuralism from postmodernism on the basis of epistemological and historiographical criteria. ${ }^{43}$ In particular, postmodernism is characterized by its neo-Romantic challenge against the Enlightenment values and

holds that knowledge is bound by space and time, that no reliable scientific knowledge exists outside the socio-political network of power relationships, and that science, as a whole, is an enterprise tainted by its association with capitalism, an enterprise that colluded and conspired to exploit the prestigious label of "scientific research" in order to impose dogmatic control over modern populations ... The modern appeal to reason is thus radically challenged as a bourgeois, elitist power play to exert social, political and economic domination. ${ }^{44}$

This approach spread quite easily within the HoR, to the point that "the wild, liberating force of poststructuralism has been domesticated into a docile pet at the service of the same ideological agendas against which postructuralism was adopted in the HoR in the first place". ${ }^{5}$

In other words: science out, mythological machines in.

\section{Science strikes back?}

The final chapter, entitled "Cognitive (R)evolution: The End?", evaluates the interdisciplinary development of scientific approaches in the study of human beliefs and behaviours throughout the $20^{\text {th }}$ century, with a special attention towards evolutionary and cognitive attempts to update the historical study of religions. The early efforts of forgotten forerunners (e.g., James M. Baldwin, Alexander Macalister) and problematic ancestors (Jane E. Harrison with both her ground-breaking, and today neglected, evolutionary psychology and her penchant for the paranormal) are briefly recalled against the backdrop of pseudoscientific psychoanalysis, noncognitive psychological behaviourism, and anti-scientific cultural anthro-

43 Ibid., 137-138. See, for instance, Johannes Angermuller, Why There Is No Poststructuralism in France: The Making of an Intellectual Generation, London - New York: Bloomsbury 2015.

44 L. Ambasciano, An Unnatural History..., 139.

45 Ibid., 143. 
pology. The most HoR-relevant works of Sigmund Freud, Sándor Ferenczi, Carl G. Jung, Joseph Campbell, John B. Watson, and Franz Boas are also taken into consideration.

By the mid-1950s, the cognitive revolution began to slowly change the social scientific approach towards culture and religion. Again, interdisciplinary anthropology was at the forefront, with scholars like Leslie White and Lewis Binford committed to breaking down the questionable distinction between nature and nurture. Meanwhile, linguist Noam Chomsky began developing a new anti-behaviourist framework that accounted for the inborn biological predisposition to develop language which, after many updates and profound modifications, proved to become a staple of the incipient evolutionary research on cognition and innateness. Other subtle signs of a more or less radical change were visible. "In the following years, steady advances in cybernetics fuelled a cross-disciplinary integration and an epistemological consilience between Artificial Intelligence, psycholinguistics, neuroscience and philosophy of mind. This fruitful collaboration resulted in a new scientific paradigm for cognitive sciences." 46 From the 1950s to the 1990s, a slow but steady resurgence of scientific approaches revitalized the old Darwinian approach to the HoR. In parallel to the previously recalled falsification of the Eliadean paradigm, some trailblazing HoR scholars, philosophers, and fellow anthropologists were trying to advance an inter-disciplinary and cognitively-based research programme within the HoR, the most important of whom were Stewart E. Guthrie, Frits Staal, William E. Paden, Walter Burkert, Luther H. Martin, E. Thomas Lawson, and Robert N. McCauley. ${ }^{47}$

In the early 2000s, following a redefinition of the entire nature vs. nurture debate, ${ }^{48}$ this renovation emerged into the birth of the cognitive and evolutionary sciences of religion and culture and to the establishment of both international associations and dedicated academic journals, most notably, the International Association for the Cognitive Science of Religion (IACSR), established in 2006, and its flagship journal, the Journal for the Cognitive Science of Religion, launched in 2013. It is important to note that the field has not returned sic et simpliciter to its Victorian roots - al-

46 Ibid., 160. Cf. William Bechtel - Adele Abrahamsen - George Graham, "Cognitive Science, History", in: Neil J. Smelser - Paul B. Baltes (eds.), International Encyclopedia of the Social and Behavioral Sciences, Oxford: Elsevier Science 2001, 2154-2158.

47 L. Ambasciano, An Unnatural History..., 161-162.

48 Ibid. Cf. John Tooby - Leda Cosmides, "The Psychological Foundations of Culture", in: Jerome H. Barkow - Leda Cosmides - John Tooby (eds.), The Adapted Mind: Evolutionary Psychology and the Generation of Culture, Oxford - New York: Oxford University Press 1992, 19-136; Dan Sperber, Explaining Culture: A Naturalistic Approach, Oxford: Blackwell 1996. 
though, in a sense, this re-appropriation has played a significant, if minimal, part in the whole process - for the Victorian paradigm per se was not deprived of flaws and biases. Instead, the current natural history of religion (s) has mostly adopted a consilient and inter-disciplinary approach while branching into four distinct sub-fields - which I have explained in some detail and length in this chapter: the experimental Cognitive Science of Religion, or CSR 2.0; the Evolutionary Science of Religion or ESR; Cognitive Historiography; and Neurohistory. 49

Notwithstanding these positive outcomes, any conclusive triumphalism would sound complacent and misguided. Despite the current bloom of such trends, a post-truth backlash still dominates the HoR, equally divided into pseudoscientific religion- or spirituality-friendly approaches, conservative and apologetic agendas, and the postmodern rejection of science. Such trends strongly oppose secular and epistemologically warranted approaches in the field. Considering the historiographical resilience of the field against science, such ideological hindrances might successfully shield the academic HoR from disconfirmation - again. 50

\section{Epilogue: The Sisyphean struggle of the HoR}

Early on in the twilight of the Victorian science of religion, "Frazer combined lucid pessimism and disillusion with an unflinching belief in science and progress, formulating a quasi-cyclical view in which science has to fight unrelentingly not to be reduced to silence by a mix of ignorance, superstition, irrationality, 'clerical resurgence' and mass manipulation by interested parties." 51 Is the HoR thus doomed to repeat this Sisyphean, futile, and humiliating struggle?

49 Methodological problems do still persist, the most troublesome of which is what I have called the "floccinaucinihilipilification of history" that affects the most experimental and quantitatively oriented branches, that is, the belittling, if not rejection, of qualitative historiography tout court. See Leonardo Ambasciano, "Exiting the Motel of the Mysteries? How Historiographical Floccinaucinihilipilification Is Affecting CSR 2.0", in: Luther H. Martin - Donald Wiebe (eds.), Religion Explained? The Cognitive Science of Religion after Twenty-Five Years, London - New York: Bloomsbury 2017, 107-122; Leonardo Ambasciano - Thomas J. Coleman, III, "History as a Canceled Problem? Hilbert's List, du Bois-Reymond's Enigmas, and the Scientific Study of Religion", Journal of the American Academy of Religion 87/2, 2019, 366-400. It is worth noting that this time around, given that an eminently scientific approach has been finally and fully embraced, this and other methodological issues will be hopefully tackled and resolved in the near future.

50 L. Ambasciano, An Unnatural History..., 99, 108, 143, 146-148, 171.

51 Ibid., 29. Cf. Marjorie Wheeler-Barclay, The Science of Religion in Britain, 1860-1915, Charlottesville: University of Virginia Press 2010, 192-193. 
In ancient Greek mythology, Sisyphus was punished for his cunning and sentenced to push a rock up to the top of a hill, only to see his efforts thanklessly crushed, for the rock was bound to roll back into the valley below each time. The history of the HoR reveals an outstanding number of scholars who tried in vain to update the scientific status of the HoR - each one a Sisyphus in his or her own peculiar way. Science is the rock that the Sisyphean scholars had - and still have - to push up the hill of religious dogmas and spiritual beliefs of any sort, whose peak is never to be conquered, for the field is bound to produce and then repeal any scientific understanding and explanation of religion(s), again and again. Building on the similarly realistic thesis advanced by Luther H. Martin and Donald Wiebe back in 2012, AUHR's "Epilogue: The Night of Pseudoscience" summarises the reasons why the ongoing appeal of cognitive biases, logical fallacies, and theological or ideological beliefs have been preventing the fully-functional, widespread implementation of a completely independent scientific study of the history of religion(s) in academia. ${ }^{52}$ Moreover, the alarming rise of both pro-religious approaches favouring the social or psychological usefulness of religion, and financial funding from religious institutions in the social-scientific study of religion and in some branches of the cognitive and evolutionary sciences of religion as well, raise serious concerns about the research directions and the infiltrations of extra-epistemic reasons behind academic research. This situation is coupled with the current socio-cultural environment dominated by accommodationist attempts, post-truth resistance to science, and postmodern reaction against Enlightenment and secular values. Meanwhile, digital fake news and posttruth echo chambers are threatening the democratic need for rational thinking and scientific literacy. While prospects for the near future are beyond our grasp, the whole history of the HoR reveals a worrisome link between the rise of academic post-truth infiltrations and reactionary, racist, and extremist politics. In these days of disciplinary post-truth recrudescence, scientific and democratic choices converge, and, while pessimistic, the ending of $A U H R$ calls for a moral choice in favour of democracy and science. 53

The HoR has carved an academic niche where pseudoscience dictates the research agenda. The success and the resilience of the field impose a

52 L. Ambasciano, An Unnatural History..., 175-176. Cf. Luther H. Martin - Donald Wiebe, "Religious Studies as a Scientific Discipline: The Persistence of a Delusion", Religio: Revue pro religionistiku 20/1, 2012, 9-18. Republished in iid. (eds.), Conversations and Controversies in the Scientific Study of Religion: Collaborative and Co-authored Essays by Luther H. Martin and Donald Wiebe, Leiden - Boston: Brill 2016, 221-230.

53 L. Ambasciano, An Unnatural History..., 178. 
critical reconsideration of any triumphant account of scientific advancement and raise a disturbing question for the future: will the scientific study of religion(s) survive the current post-truth era? 


\section{SUMMARY}

\section{The Sisyphean Discipline: A Précis of "An Unnatural History of Religions"}

The present contribution offers a recapitulation of the author's book entitled An Unnatural History of Religions: Academia, Post-truth and the Quest for Scientific Knowledge (2019). The book is intended to offer a most comprehensive account of the History of Religions as an academic discipline, from its inception as a Victorian science of religion to the postmodern rejection of master narratives and from the birth of contemporary Religious Studies to the recent resurgence of cognitive and evolutionary approaches.

One of the major themes to emerge from the historiographical analysis is the constant disciplinary temptation to move aside scientific explanations in favour of fideistic redescriptions. Ever struggling to come to terms with science, the historical study of religions in all the major national schools of the past considered here has reaffirmed time and again the absolute value of religion as epistemic truth, delegitimizing, depreciating, and discarding scientific and rational tools as useless for grasping the inner core of human consciousness.

Keywords: cognition; evolution; historiography; History and Philosophy of Science; History of Religions; method and theory; post-truth.

\section{Journal of Cognitive Historiography Managing Editor}

LEONARDO AMBASCIANO leonardo.ambasciano@gmail.com 